\title{
Serum-insulin response to glucose in 'pancreatic diabetes'
}

\author{
SIMMY BANK \\ M.B., M.R.C.P.(Lond.) \\ Consultant Gastroenterologist \\ P. KeLleR \\ Ph.D. (Freiburg) \\ Chief Research Officer
}

\author{
W. P. U. JACKSON \\ M.D., F.R.C.P.(Lond.) \\ Associate Professor of Medicine \\ I. N. MARKS \\ B.Sc., M.B., F.R.C.P.(Edinb.) \\ Head, Gastrointestinal Unit
}

The Gastrointestinal and Endocrine Units, Groote Schuur Hospital, and

Department of Medicine, University of Cape Town, Observatory, Cape, South Africa

\section{Summary}

Thirty patients with chronic pancreatitis (mostly calcific) were tested for glucose tolerance and serum insulin response to glucose loading. The responses were very variable and the insulin values did not clearly relate to the 'glucosetolerance-status'. Some subjects had low insulin levels throughout, some had average to high fasting levels without further response, and some showed an excellent rise of insulin level after glucose.

No antibodies to insulin could be found in seven patients. Synalbumin antagonist was present at $1.25 \%$ in five out of twelve patients tested.

\section{Introduction}

In recent communications we have reported that patients with diabetes secondary to pancreatitis may have normal or even raised fasting serum insulin levels as measured as insulin-like activity (ILA) or immunoreactive insulin (IRI) and that patients with symptomatic 'pancreatic diabetes' not infrequently respond to oral hypoglycaemic agents including those drugs that stimulate insulin secretion, i.e. the sulphonylureas (Keller et al., 1965 ; Marks \& Bank, 1965 ; Bank, 1966).

The present paper reports the serum immunoreactive insulin (IRI) levels after provocation with glucose in patients with pancreatitis with normal and abnormal glucose tolerance and overt pancreatic diabetes. Estimations of insulin-antibodies and of albumin antagonism were also made in some cases.

\section{Patients}

Fasting and post-glucose serum IRI were measured in thirty patients with chronic pancreatitis; in twenty-eight of these alcohol was considered to be the major aetiological factor and no cause could be established in the remaining two. Twenty-six of the patients were males ranging from 20 to 50 years of age and four were females ranging from 40 to 55 years. None of the patients had a family history of diabetes and the diabetes post-dated the onset of typical attacks of pancreatitis by months or years in all the patients.

The patients were divided into four groups according to their glucose tolerance and the severity of the diabetic state. Insulin-taking diabetics were omitted.

Group 1 consisted of eleven patients with normal glucose tolerance and long histories of relapsing pancreatitis. Eight of the eleven patients had calcific pancreatitis, two had surgical confirmation of the disease and one had recurrent attacks of alcohol-induced pancreatitis and abnormal pancreatic function on testing (Bank et al., 1963). Two patients gave a history of intermittent steatorrhoea and one had steatorrhoea on stool analysis.

Group 2 comprised three patients with calcific pancreatitis who had abnormal glucose tolerance on routine testing. Two of these had steatorrhoa.

Group 3 consisted of six patients with frankly diabetic glucose tolerance tests on routine testing but free of symptoms. Calcification was present in five of the patients and the diagnosis of pancreatitis was confirmed surgically in the remaining one. Steatorrhoea was present in three cases.

Group 4 comprised ten patients with symptomatic diabetes who were taking oral hypoglycaemic agents for control of symptoms. Pancreatic calcification was present in six patients, three had previously had surgical confirmation of the disease and the diagnosis in the remaining one 
was based on typical attacks of alcoholic pancreatitis and abnormal pancreatic function on testing. Four patients had steatorrhoea.

Twenty of the thirty patients had previously had a liver biopsy and in nine the macroscopic appearance of the liver was available from laparotomy findings. Only one patient had clinical and histological cirrhosis. The patients in whom serum albumin was investigated for insulin antagonism were all male, under the age of 45 and without any known diabetics in their families.

\section{Methods}

Oral hypoglycaemic agents were discontinued at least 5 days before the tests were carried out. The serum insulin levels were estimated in venous blood taken from the thirty patients in the fasting state and at the 1- and 2-hr period of a standard 2-hr glucose tolerance test, utilizing $50 \mathrm{~g}$ of oral glucose solution. Blood sugar determinations were carried out on capillary blood by the method of Hagedorn-Jensen (more recently by AutoAnalyzer and Hoffman method). The criteria for diagnosis of diabetes have previously been discussed (Jackson, 1964). All the serum insulins were determined by the immunoassay technique of Hales \& Randle (1963). Insulin antibodies were determined by the method of Yalow \& Berson (1961) and synalbumin insulin antagonism by that of Vallance-Owen, Dennes \& Campbell (1958a, b).

\section{Results}

Fig. 1 shows the fasting, 1-hr and 2-hr serum IRI levels in the four groups of patients. The individual insulin results were extremely variable in all groups. The majority of patients showed at least some rise in serum insulin levels at the 1 -hr period of the glucose tolerance with a fall at the 2nd hour, a few showed a rise in the 2nd hour only and a small number showed either no change or an actual reduction of serum insulin levels when compared to the fasting level.

Table 1 shows an arbitrary grading of the serum insulin response to provocation with glucose in the four groups of patients. A 'good rise' in IRI indicates at least a four-fold increase and a level of over $20 \mu \mathrm{u} / \mathrm{ml}$. Ten of the eleven patients with normal glucose tolerance tests showed some insulin response to glucose and of these four showed a 'good rise'. We have not attempted to correlate plasma insulin and glucose levels. (A single very high fasting value has been omitted as probably an artifact.) The insulin response to glucose was less impressive in the group of patients with frankly diabetic toler- ance tests. Five of these sixteen patients, however, showed a 'good' serum insulin response to glucose loading. Two of the five were patients receiving oral hypoglycaemics and one had associated cirrhosis of the liver.

\section{Insulin antibodies}

No antibodies to beef insulin were detected in any of eight patients, seven of whom had calcific pancreatitis.

\section{Synalbumin antagonist}

Antagonism of $1.25 \%$ albumin to insulin action on the rat diaphragm was studied in twelve cases. It was present (i.e. the serum was 'antagonistic') in five, judged by the criteria of Vallance-Owen (Vallance-Owen et al., 1958a, b). Four of the five patients had calcific pancreatitis and three were overtly diabetic. None needed insulin. In three the antagonism was complete (i.e. the glucose uptake produced by the insulin was totally abolished). For comparison, in twenty-three normal control subjects antagonism was present in six, while in twelve apparently 'genetic diabetics' attending the Diabetes Clinic, antagonism was present in seven.

\section{Comment}

It is generally assumed that diabetes caused by chronic pancreatitis is due to simple destruction of the beta cells. We previously observed that some 'pancreatic diabetics' actually had rather high fasting levels of serum insulin and also that some were well-controlled with oral sulphonylurea drugs (Keller et al., 1965 ; Bank, 1966). It appears, then, that the pancreas in such patients is capable of secreting sufficient insulin for their needs. The present observations indicate that there is great variation in the response of different patients with chronic pancreatitis to glucose. Some subjects, in all categories of glucose tolerance, were very poor secretors of insulin, with little or no response to glucose. On the other hand, some patients with symptomatic diabetes produced a good insulin output after glucose stimulation. The three best responses, as one might expect, had normal glucose tolerance but it is not clear why some patients with normal tolerance had virtually no insulin output. A few subjects with normal fasting levels of insulin showed no response to glucose. This suggested that the partially damaged beta cells were already responding maximally in such patients (Peters et al., 1966) but it should be noted that the early insulin responses (after 10-20-30 min) were not measured in our cases-this is being investigated at present. 

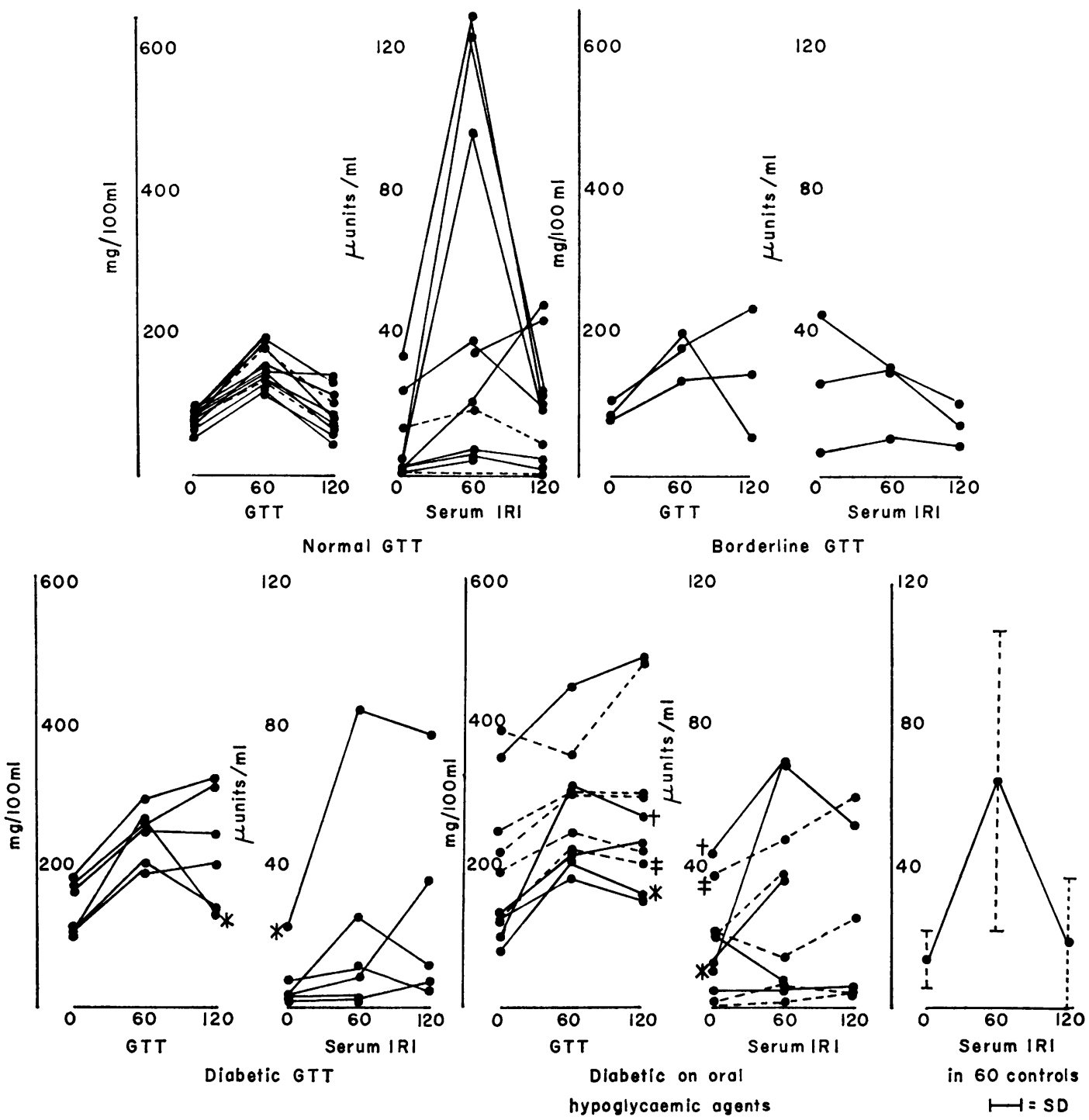

FIG. 1. Glucose tolerance and serum insulin levels in the four groups of patients with pancreatitis. Serum IRI in sixty controls is included for comparison. ${ }^{*}, t, \ddagger=$ corresponding patients.

TABLE 1

Arbitrary grading of serum insulin response during the standard glucose tolerance test in the thirty patients with pancreatitis

\begin{tabular}{|c|c|c|c|c|c|c|c|c|}
\hline \multirow{3}{*}{\multicolumn{2}{|c|}{ Group }} & \multicolumn{7}{|c|}{ Insulin response after glucose } \\
\hline & & \multicolumn{2}{|c|}{$\begin{array}{c}\text { Good rise } \\
\text { (at least four-fold } \\
\text { and over } 20 \mu \text { units) }\end{array}$} & \multicolumn{2}{|c|}{ Lesser rise } & \multirow[t]{2}{*}{$\begin{array}{c}\text { No } \\
\text { change }\end{array}$} & \multirow[t]{2}{*}{ Fall } & \multirow[t]{2}{*}{ Total } \\
\hline & & 1st hour & 2nd hour & Moderate & Slight & & & \\
\hline 1. & Normal GTT & 4 & 0 & 1 & 5 & 1 & $\mathbf{0}$ & 11 \\
\hline & Borderline GTT & - & - & 2 & - & - & 1 & 3 \\
\hline & Diabetic GTT & 2 & 1 & 0 & 1 & 2 & - & 6 \\
\hline & Diabetic on oral the & rapy 2 & 0 & 3 & 2 & 1 & 2 & 10 \\
\hline \multicolumn{2}{|c|}{ Total } & 8 & 1 & 6 & 8 & 4 & 3 & 30 \\
\hline
\end{tabular}


Insulin antibodies were looked for in case islet destruction had led to an immune response and hence the development of diabetes possibly on an autoimmune basis. No evidence was found to support this hypothesis.

The presence of synalbumin antagonism in the sera of several patients (five out of twelve) does not necessarily incriminate this substance in the pathogenesis of the diabetes of chronic pancreatitis, since it was also present in some $25 \%$ of normal control subjects. If this antagonist is in fact the B-chain of insulin it is noted that the damaged islet-cells in chronic pancreatitis are still capable of producing it in high concentration.

\section{Acknowledgments}

We would like to thank Dr B. Pimstone (Physician) for carrying out the insulin antibody studies and Mr I. G. O'Reilly for technical assistance.

This study was supported by the South African Council for Scientific and Industrial Research, the Ben May Fellowship and the Hermann Bequest.

\section{References}

BANK, S. (1966) The management of diabetes in the underprivileged with special reference to pancreatic diabetes. S. Afr. med. J. 40, 342.

Bank, S., Marks, I.N., Moshal, M.G., Efron, G. \& Silber, R. (1963) The pancreatic function test-method and normal values. S. Afr. med. J. 37, 1061.

HALES, C.N. \& RANDle, P.J. (1963) Immuno-assay of insulin with insulin-antibody precipitator. Biochem. J. 88, 137.

JACKsON, W.P.U. (1964) On Diabetes Mellitus, Chap. 8. Thomas, Springfield, Illinois.

Keller, P., Bank, S., Jackson, W.P.U., Marks, I.N. \& O'Reilly, I.G. (1965) Plasma insulin levels in 'pancreatic diabetes'. Lancet, ii, 1211.

MARKS, I.N. \& BANK, S. (1965) Treatment of pancreatic diabetes. Modern Treatment (Ed. by H. M. Pollard), p. 471. Hoeber, New York.

Peters, N., Dick, A.P., Hales, C.N., Orrell, D.H. \& SARNer, M. (1966) Pancreatic diabetes. Lancet, i, 95.

Vallance-Owen, J., Dennes, E. \& Campbell, P.N. (1958a) Insulin antagonism in plasma of diabetic patients and normal subjects. Lancet, ii, 336.

Vallance-Owen, J., Dennes, E. \& Campbell, P.N. (1958b) The nature of the insulin-antagonist associated with plasma albumin. Lancet, ii, 696.

YALOW, R.S. \& BERSON, S.A. (1961) Immunologic aspects of insulin. Amer. J. Med. 31, 882. 